\section{Dual role for Pluto in the great planetary debate}

SIR — The discovery of 2003 UB313, an object larger and farther away than Pluto, has once again stimulated the debate on how we define a planet (Nature 436, 616; 2005). The official status of 2003 UB313 will be decided by the International Astronomical Union (IAU). Meanwhile, in the manuscript for a forthcoming book, I have just changed a section heading from "Eight planets?" to “Ten planets!". But how should we decide how many planets there are?

I believe that Pluto should remain the ninth planet, as it has been for the past 75 years, and we should enjoy teaching about how this planet differs from the others. Being different is not reason enough to exclude Pluto from the list of planets: in recent years Uranus and Neptune have been found to differ greatly from Jupiter and Saturn, which themselves differ greatly from the terrestrial planets.

I believe that 2003 UB313 should be called the tenth planet, because it is both larger than Pluto and at an appreciably different distance, although a practical problem the IAU will then have to face is where to draw the line at the lower end of sizes. For example, should Sedna or 2003 EL61 - each roughly threequarters the size of Pluto - also be named planets? I propose that the size of Pluto should be considered the lower limit, for historical reasons.

It is important to remember that Pluto and 2003 UB313 are also 'Trans-Neptunian objects' - bodies orbiting the Sun at a greater distance than Neptune - and that these differ from the eight large planets, especially in their origin as small asteroidal aggregates. In order to preserve this distinction, Pluto and 2003 UB313 should also be given asteroid identifications.

\section{Tom Gehrels}

Department of Planetary Sciences,

University of Arizona, Tucson,

Arizona 85721, USA

\section{Extra controls will waste yet more research time}

SIR - Your Editorial "Rules of engagement" (Nature 436, 2; 2005) discusses the need for biologists to adhere to new codes of conduct. But is further control of biological research really necessary?

In recent years, some urgently needed controls have been adopted. In Brazil, all projects that will involve human or animal experimentation must be submitted to an ethical or animal-use committee for consideration, and any research using genetically modified organisms must be approved in advance by a federal committee.

In addition, most Brazilian research is preceded by an application for funding, which ensures that projects are refereed by two or more peers before approval. Any resulting manuscripts submitted to accredited journals are again reviewed, with referees in many cases being specifically asked to judge all possible outcomes or uses of the research. In my institute, professional practice in all laboratories is also evaluated by a panel of internal and external investigators every four years.

There is a danger that implementing further controls would simply add to the number of time-consuming obstacles that already make competitive research all but impossible.

\section{Vera Bongertz}

Lab AIDS \& Imunologia Molecular/IOC/

FIOCRUZ, Avenida Brasil 4365,

21045-900 Rio de Janeiro, RJ, Brazil

\section{Complex research on sea lions is worth the expense}

SIR - Your News story "Is this any way to save a species?" (Nature 436, 14-16; 2005) implies that US taxpayers were not well served by the narrow funding of about $\$ 120$ million between 2001 and 2004 to promote the recovery of an endangered population of Steller sea lions. I disagree with this suggestion.

Alaska produces roughly half of the United States' commercial fisheries landings by volume. The economic foundations for most coastal communities in the Gulf of Alaska and Bering Sea are marine-fisheries products, and the families that live in these communities would be hard pressed to make a living without these fisheries. From this perspective, an investment in research and management over a four-year period of less than $10 \%$ of the annual value of the fishery seems prudent. In any event, the legal impasse that had been reached between the National Oceanic and Atmospheric Administration (NOAA) and the environmental group bringing suit would have resulted in an estimated loss of annual revenue of between $\$ 200$ million and $\$ 500$ million.

Another important point is that the $\$ 120$ million supported not only research on Steller sea lions in Alaska, but a complex ecosystem-based research programme. The Congressional language referred to in your article directed NOAA to conduct research on a comprehensive set of factors that might have contributed to the decline in abundance of sea lions. These include climate change in the Gulf of Alaska and the Bering Sea, pollution, disease, deaths caused by human involvement (such as entanglement in marine debris, poaching, vandalism and Alaska native subsistence harvests) and the impacts of predators on sea lions and of commercial fisheries on Steller sea lions' prey fishes. Research on all these factors was carried out at varying levels of sophistication. In addition, NOAA used these funds to support various management activities relevant to the two populations of Steller sea lions in Alaska.

Although it is too early to conclude that a recovery is under way, and too soon to definitively assign cause and effect, the conservation measures developed by the North Pacific Fishery Management Council and implemented by NOAA are associated with the first increase in abundance in the western population of Steller sea lions in more than 30 years. If this trend continues for two more biennial censuses, this population will indeed be recovering.

Of course, $\$ 120$ million is a great deal of money. Doing research in the difficult field conditions of Alaskan waters is expensive and time-consuming, particularly given the enormous distances covered in the sea lions' geographical range. Although many environmental issues remain to be addressed, the example in Alaska shows that it is possible to achieve sustainable fishing as well as protection of endangered species. William Hogarth

NOAA Fisheries Service, National Oceanic and Atmospheric Administration, US Department of Commerce, 1315 East-West Highway, Silver Spring, Maryland 20910, USA

\section{A woman's place in Nature}

SIR - It is astonishing to find, in the celebrated new format of Nature, a prominent transcription of the 1869 Nature mission statement : “...to aid scientific men themselves...".

This assertion harks back to archaic times when women had not achieved recognition in science. It does not correspond to the open spirit that has, for a long time, characterized Nature and it should be modified in line with the present, more equitable, times.

Fabio Salamanca-Buentello*, Leonor BuentelloMalo†', Fabio Salamanca-Gómezł

*Joint Centre for Bioethics and Canadian Program on Genomics and Global Health, University of Toronto, Toronto, Ontario M5G 1L4, Canada $\dagger$ Institute of Research in Anthropology, UNAM, Ciudad Universitaria, México, DF 04510, Mexico YUnit of Medical Research in Human Genetics, Apartado postal 12-951, México, DF 03020, Mexico

Contributions to Correspondence may be submitted to corres@nature.com. They should be no longer than $\mathbf{5 0 0}$ words, and ideally shorter. Published contributions are edited. 